\title{
Does D3 surgery offer a better survival outcome compared to D1 surgery for gastric cancer? A result based on a hospital population of two decades as taking D2 surgery for reference
}

\author{
Hao Zhang ${ }^{1+}$, Caigang $\mathrm{Liu}^{1+}$, Di Wu${ }^{2+}$, Yi Meng ${ }^{3}$, Ruonan Song ${ }^{4}$, Ping $\mathrm{Lu}^{1 *}$, Shubao Wang ${ }^{1}$
}

\begin{abstract}
Background: We conducted a retrospective study in our hospital in which we compared D1 with D3 through D2 lymphadenectomy for gastric cancer in terms of morbidity, postoperative mortality, long-term survival after surgery. Methods: 567 patients who were performed curative intent between 1980 and 2003 were enrolled. 187 in the D1 group, 189 in the D2 group and 191 in the D3 group. Every procedure was verified by pathological analyses. The primary endpoints were 5-year overall survival.

Results: Median follow-up periods were 36 months and 60 months for D1 group and D3 group. Overall 5-year survival rate was significantly higher in patients underwent D3 surgery than in those performed D1 surgery (37.4\% vs 48.7\%; log-rank, $p=0.027$ ). For the cases followed up to 120 months, the 10 -year overall survival rate was $29 \%$ (95\% Cl, $22.1 \%$ to $35.9 \%)$ for the D1 group and $33.7 \%$ (95\% Cl, 26.6\% to 40.8\%) for the D3 group (log-rank, $\mathrm{p}=$ 0.005).

Conclusions: D1 surgery should be operated only for patients with Borrmann I disease. As D3 gastrectomy is associated with low mortality and adequate survival times when performed in selected institutions that have had sufficient experience with the operation and with postoperative management, we recommend D3 lymphadenectomy for patients with curable gastric cancer.
\end{abstract}

\section{Background}

Gastric cancer is still the most common cause of cancer related deaths worldwide, and a major clinical problem needing to be resolved because of the poor prognosis and the leak of treatment methods. Nowadays, surgical management is the major treatment method for gastric cancer. However, the efficacy of various extent of nodal dissection is still under debate. It was reported that improved prognosis was got in patients with gastric cancer who underwent D3 lymphadenectomy (first edition of Japanese classification of gastric cancer[1-3]. Furthermore, there were some randomised multi-institutional trials showing no survival benefits, but high morbidity

\footnotetext{
* Correspondence: luping2999@yahoo.com.cn

+ Contributed equally

'Department of Surgery Oncology, General Surgery, First Hospital of China Medical University, Shenyang, China
}

(C) 2010 Zhang et al; licensee BioMed Central Ltd. This is an Open Access article distributed under the terms of the Creative Commons Attribution License (http://creativecommons.org/licenses/by/2.0), which permits unrestricted use, distribution, and reproduction in any medium, provided the original work is properly cited. and mortality, after D3 gastric dissection compared with D1 dissection[4,5]. To be mentioned, there were many participating surgeons with little experience in D3 surgery in these trials, hence, it's difficult to control the quality[4,5].

The more extended the surgery, the greater the risk of operation related morbidity and mortality is, as reported previously that nodal dissection increased morbidity[6]. It was reported that the postoperative mortality rate for gastrectomy surgery often exceeds $5 \%$ in West, even gets close to $16 \%$ in some articles,[7-9] only some Japanese studies reported a lower than $2 \%[10]$. Besides the operation related morbidity, there was also a report showing that lymph node dissection did not adversely influence QOL,[11] and the operation related morbidity did not influence survival[12,13]. 
We conducted a single-institutional study and reported the long-term survival data for these two surgical groups of D1 and D3 taking D2 group as reference. Finally, we demonstrated that D3 surgery has overall survival benefit without significant operative complications and mortality.

\section{Methods}

\section{Patients}

We selected 567 patients who were histologically confirmed gastric cancer and underwent a radical operation at the First Affiliated Hospital of the China Medical University between 1980 and 2005. All of them, 187 were performed D1 dissection (D1 group), 189 received D2 surgery (D2 group) and 191 were treated with D3 dissection (D3 group). The inclusion criteria were as follows: 1 ), histologically proven, potentially curablengastric adenocarcinoma, and had physical fitness suitable for elective operation of either type of lymphadenectomy; 2), diagnosed based on the 5th UICC TNM classification system; 3), curative D1, D2 or D3 operations were performed; 4), a complete medical record was available; 5), patients of every period of diagnosis and every surgeon are roughly equal; and 6), never received neoadjunctive therapies and any kind of adjunctive therapy. Exclusion criteria were as follows: 1), older than 75 years; 2 ), previous or concomitant other cancer; 3 ), previous or concomitant gastrectomy for benign disease; 4), previous chemotherapy or radiotherapy; 5), clinical evidence of early gastric cancer on laparotomy; 6), oesophageal involvement; 7), macroscopically enlarged lymph nodes around the hepatoduodenal ligament or para-aortic regions; and 8), distant metastatic disease.

All patients were followed up by posting letters or telephone interviews. The last follow-up was December, 2008. Clinical findings, surgical findings, pathological findings and every follow-up were collected and recorded in the database. All the subjects gave written informed consent to study protocol, which was approved by the Ethics Committee of China Medical University.

\section{Surgical procedures and classifications of gastric cancer}

Surgical procedures and pathological assessment refered to the Japanese classification of gastric cancer[1]. All patients in the study underwent standard total or distal subtotal gastrectomy, depending on the location and macroscopic appearance of the primary tumor. The definition of lymphadenectomy was based on the Japanese Classification of Gastric Carcinoma[5]. D1-dissection of all the group 1 nodes; D2-dissection of all the group 1 and group 2 nodes; D3-dissection of all the group 1, group 2 and group 3 nodes. Group 1 consists of the perigastric lymph nodes, and group 2 consists of the lymph nodes along the left gastric artery, the common hepatic artery, and the splenic artery and around the celiac axis. However, when the tumor is located in the lower third stomach, the lymph nodes along the splenic artery are classified as group 3. Group 3 also consists of lymph nodes in the hepatoduodenal ligament at the posterior aspect of the head of the pancreas and at the root of the mesentery.

Surgeons routinely removed lymph nodes from the excised specimens as more as possible after operation, based on the Japanese Classification of Gastric Carcinoma and their experience. The specimens and retrieved lymph nodes were stained with hematoxylin and eosin and pathologically examined in the Gastric Laboratory of the First Affiliated Hospital of the China Medical University.

\section{Endpoints and follow-up}

The primary endpoints were 5-year overall survival. Overall survival was calculated from the day of surgery until death or the last follow-up contact. Data for a patient were censored at last follow-up when they were alive. Follow-up assessments were done every 6 months for the first 5 years after surgery, and then every 12 months until death.

\section{Statistical analyses}

Data from all eligible patients were analyzed for overall survival. Survival curves were estimated by the KaplanMeier method and treatment comparisons were made by the log-rank test.

Potential prognostic factors were entered into a Cox's regression model including age, sex, tumor size, site of tumour in stomach, gross appearance, tumour stage, clinical node status, nodal stage, joint organ removal, gastrectomy, blood transfusion and blood loss. In multivariate analysis, the prognostic factor detected in univariate analysis and treatment group were as covariates included in the Cox regression model.

Two-sided $\mathrm{P}$ values were calculated for all tests and are reported here. $P$ values less than 0.05 were considered to indicate statistical significance. Analyses were performed with the use of SPSS software, version 16.0.

\section{Results}

D1 group was with median age of 55 years old, D2 group was with median age of 55 years old and D3 group was with median age of 54 (table 1). All patients were followed up for at least 5 years (until December 19, 2008).

The characteristics of the three groups, which were showed in table 1 , were well balanced. 125 patients had early cancer (confined to submucosa or mucosa). 536 patients had curative resection; 31 patients had palliative 
Table 1 Characteristics of D1, D2, D3 population $(n=567)$

\begin{tabular}{|c|c|c|c|c|}
\hline Characteristics & D1 surgery $(n=187)$ & D2 surgery $(n=189)$ & D3 surgery $(n=191)$ & p Value \\
\hline Age (years) & & & & 0.899 \\
\hline Median & 55 & 55 & 54 & \\
\hline $\operatorname{Sex}(\%)$ & & & & 0.758 \\
\hline Men & $136(73)$ & $137(73)$ & $133(70)$ & \\
\hline Women & $51(27)$ & $52(27)$ & $58(30)$ & \\
\hline Number of lymph nodes removed & & & & 0.189 \\
\hline Mean & 21 & 23 & 26 & \\
\hline Number of involved lymph nodes & & & & 0.232 \\
\hline Mean & 3 & 4 & 6 & \\
\hline Tumor size(\%) & & & & 0.323 \\
\hline$\leq 5 \mathrm{~cm}$ & $125(67)$ & $121(64)$ & $113(59)$ & \\
\hline $5-7 \mathrm{~cm}$ & $32(17)$ & $40(21)$ & $50(26)$ & \\
\hline$>7 \mathrm{~cm}$ & $30(16)$ & $28(15)$ & $28(15)$ & \\
\hline Site of tumour(\%) & & & & 0.984 \\
\hline Upper stomach & $44(24)$ & $39(21)$ & $42(22)$ & \\
\hline Middle stomach & $43(23)$ & $50(27)$ & $45(24)$ & \\
\hline Lower stomach & $88(47)$ & $87(46)$ & $90(47)$ & \\
\hline Whole stomach & $12(6)$ & $13(6)$ & $14(7)$ & \\
\hline Pathological tumour stage(\%) & & & & 0.979 \\
\hline $\mathrm{T} 1$ & $41(22)$ & $40(21)$ & $44(23)$ & \\
\hline $\mathrm{T} 2$ & $44(24)$ & $45(24)$ & $42(22)$ & \\
\hline $\mathrm{T} 3$ & $89(48)$ & $87(46)$ & $92(48)$ & \\
\hline $\mathrm{T} 4$ & $13(6)$ & $17(9)$ & $13(7)$ & \\
\hline Clinical node status(\%) & & & & 0.729 \\
\hline Positive & $182(97)$ & 186(98) & $186(97)$ & \\
\hline Negative & $5(3)$ & $3(2)$ & $5(3)$ & \\
\hline \multicolumn{5}{|l|}{ Pathological nodal stage $(\%)^{*}$} \\
\hline NO & 69(37) & $60(32)$ & $69(36)$ & 0.500 \\
\hline N1 & $75(40)$ & $93(49)$ & $81(42)$ & \\
\hline N2 & $30(16)$ & $26(14)$ & 24(13) & \\
\hline N3 & $13(7)$ & $10(5)$ & $17(9)$ & \\
\hline Gross type(\%) & & & & 0.998 \\
\hline Borrmann I & $58(31)$ & $56(30)$ & $54(28)$ & \\
\hline Borrmann ॥ & $41(22)$ & $44(23)$ & $43(23)$ & \\
\hline Borrmann III & 73(39) & $74(39)$ & $77(40)$ & \\
\hline Borrmann IV & $15(8)$ & 15(8) & $17(9)$ & \\
\hline Histological type(\%) & & & & 0.867 \\
\hline Differentiated & $99(53)$ & $88(47)$ & $82(43)$ & \\
\hline Undifferentiated & $88(47)$ & $101(53)$ & $109(57)$ & \\
\hline Curative resection(\%) & $174(93)$ & $181(96)$ & $181(95)$ & 0.503 \\
\hline Type of gastrectomy(\%) & & & & 0.440 \\
\hline Total & $22(12)$ & $21(11)$ & $29(15)$ & \\
\hline Subtotal & $165(88)$ & $168(89)$ & $162(85)$ & \\
\hline Combined organ resection & & & & 0.283 \\
\hline Pancreas or spleen & $7(4)$ & $16(9)$ & $14(7)$ & \\
\hline Liver or gall & $11(6)$ & $8(4)$ & $9(5)$ & \\
\hline Transverse colon & $9(5)$ & $17(9)$ & $11(6)$ & \\
\hline Blood transfusion(\%) & $100(54)$ & $104(55)$ & $111(58)$ & 0.652 \\
\hline
\end{tabular}

*N1 = 1-6 involved nodes; N2 = 7-15 involved nodes; N3, >15 involved nodes. 


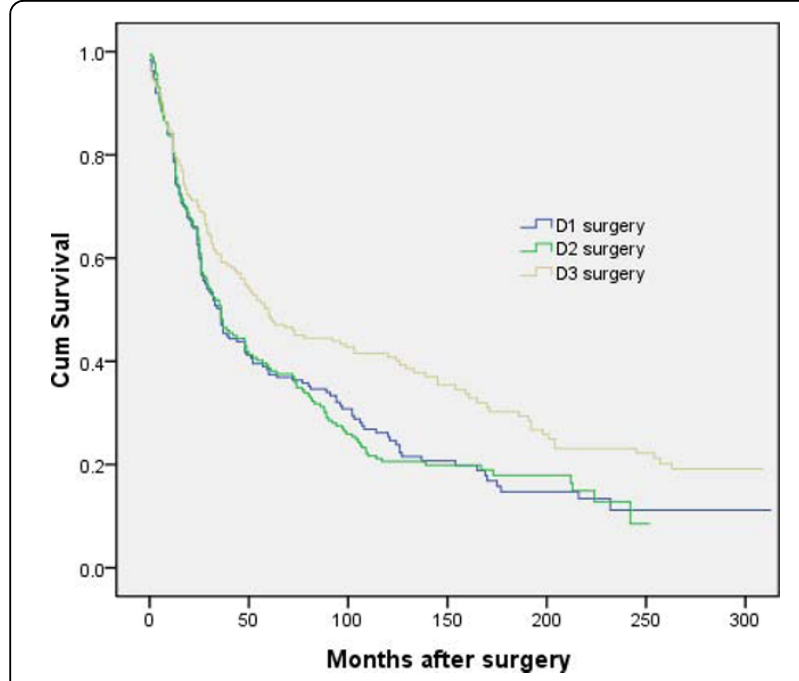

Figure 1 The overall rates for all enrolled patients. There were significant differences between D1 and D3 group ( $p=0.004)$, and between D2 and D3 group ( $p=0.002)$. However, there was no significant difference between D1 and D2 group. resection. $22(12 \%)$ patients in D1 group was performed total gastrectomy, 21 patients assigned to D2 group (11\%) and in 29 patients assigned to D3 surgery (15\%). The incidence rates of the four major surgery-related complications in the D1 group, D2 group and D3 group were $2 \%(4 / 187), 2 \%(4 / 189)$ and $2 \%(3 / 191)$, respectively, for anastomotic leakage; 4\% (8/187), 4\% (7/189) and 5\% (9/191) for pancreatic fistula; $4 \%(8 / 187), 5 \%$ $(10 / 189)$ and $5 \%(10 / 191)$ for abdominal abscess, and $4 \%$ (7/187), 2\% (3/189) and 1\% (2/191) for pneumonia. None of these differences were statistically significant (all $\mathrm{P}>0.05$ ). The hospital death rate was $2 \%$ (three deaths in D1 group, one death in D2 group and six deaths in D3 group).

After median follow-up periods of 36 months, 36 months and 60 months for D1 group, D2 group and D3 group respectively, 150 patients in D1 group, 157 patients in D2 group and 137 in D3 group died. Neither the skill of an individual surgeon nor the period of diagnosis affected survival ( $\mathrm{p}>0.05, \log$-rank test). Figure 1 and figure 2 show the overall rates for all enrolled patients. There were significant differences between D1 and D3 group $(\mathrm{p}=0.004)$, and between D2 and D3 group $(\mathrm{p}=0.002)$. However, there was no significant difference between D1 and D2 group. The 5-year overall survival was $37.4 \%$ (95\% CI, $30.5 \%$ to $44.3 \%$ ) for the D1 group and $48.7 \%$ (95\% CI, $41.6 \%$ to $55.8 \%$ ) for the D3 group (log-rank $\mathrm{p}=0.027$ ), and for those whose followup periods were up to 120 months, the 10 -year overall survival was $29 \%$ ( $95 \% \mathrm{CI}, 22.1 \%$ to $35.9 \%$ ) for the D1 group and $33.7 \%$ ( $95 \% \mathrm{CI}, 26.6 \%$ to $40.8 \%$ ) for the D3 group $(\log$-rank $\mathrm{p}=0.005)$.

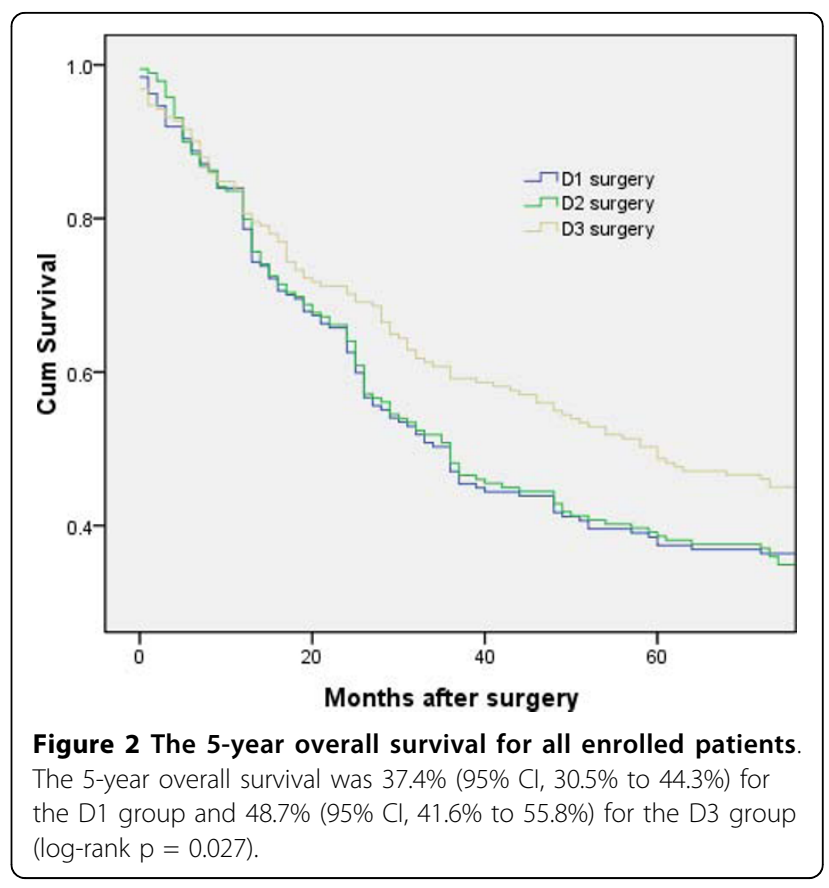

The hazard ratio for death was 0.708 (95\% CI, 0.560 0.894; $\mathrm{p}=0.004$ ) in the D3 group (table 2, univariable analyses). After adjustment of thirteen baseline variables (age, sex, tumor size, tumor location, Borrmann type, $\mathrm{T}$ stage, clinical node status, lymph-node stage, histological type, joint organ removal, gastrectomy, blood transfusion and blood loss) with the use of Cox regression analysis, the hazard ratio was hardly unchanged (hazard ratio, 0.771 (95\% CI, 0.599-0.992); $\mathrm{P}=0.043$ ) (table 2, multivariable analyses). Expectedly, the multivariate analyses showed that $>7 \mathrm{~cm}$ in tumor size, the upper third tumor and the whole stomach tumor, Borrmann III type, N3 disease, D1 and D2 dissection were significantly associated with poor survival (table 2).

As shown in table 3 and 4, D1 group got significantly more benefit than D2 or D3 group only for Borrmann I and N3 disease, the hazard ratios for death in the D1 group were $0.618(95 \% \mathrm{CI}, 0.399-0.958 ; \mathrm{P}=0.031)$ and 0.369 (95\% CI, 0.162-0.841; $\mathrm{P}=0.018$ ), respectively.

D3 group has significantly more benefit than D1 and D2 surgery in the subgroups of cases with $\leq 5 \mathrm{~cm}$ and $>7 \mathrm{~cm}$ tumors, the lower third tumor, Borrmann II and III types, T3 stage, positive clinical node, N0 and N1 disease, no joint organ removal, the subtotal gastrectomy, blood transfusion and 200-400 ml blood loss. There was no evidence indicating that D2 surgery has any significant benefit for these subgroups.

\section{Discussion}

In the study, we found significant improvement in overall survival with D3 surgery compared to D1 surgery. 
Table 2 HR for death in intention-to-treat population $(n=567)$-univariable and multivariable analyses

\begin{tabular}{|c|c|c|c|c|}
\hline & \multicolumn{2}{|c|}{ Univariable analyses } & \multicolumn{2}{|c|}{ Multivariable analyses } \\
\hline & HR $(95 \% \mathrm{Cl})$ & $\mathrm{p}^{*}$ & HR $(95 \% \mathrm{Cl})$ & $\mathrm{p} \dagger$ \\
\hline Age (years) & & 0.033 & & 0.335 \\
\hline$\leq 55$ & 1 (Ref) & & 1 (Ref) & \\
\hline$>55$ & $1.231(1.017-1.490)$ & 0.033 & $1.224(0.982-1.524)$ & 0.335 \\
\hline Sex & & 0.816 & & 0.960 \\
\hline Women & 1 (Ref) & & 1 (Ref) & \\
\hline Men & $1.025(0.833-1.261)$ & 0.816 & $0.943(0.748-1.188)$ & 0.960 \\
\hline Tumor size & & 0.000 & & 0.111 \\
\hline$\leq 5 \mathrm{~cm}$ & 1 (Ref) & & 1 (Ref) & \\
\hline $5-7 \mathrm{~cm}$ & $1.527(1.217-1.917)$ & 0.000 & $1.266(0.991-1.617)$ & 0.059 \\
\hline$>7 \mathrm{~cm}$ & $1.728(1.338-2.233)$ & 0.000 & $1.397(1.005-1.943)$ & 0.047 \\
\hline Tumour site & & 0.101 & & 0.005 \\
\hline Upper stomach & 1 (Ref) & & 1 (Ref) & \\
\hline Middle stomach & $0.624(0.477-0.816)$ & 0.001 & $0.585(0.436-0.786)$ & 0.000 \\
\hline Lower stomach & $0.626(0.495-0.792)$ & 0.000 & $0.634(0.482-0.833)$ & 0.001 \\
\hline Whole stomach & $1.303(0.889-1.910)$ & 0.174 & $0.698(0.422-1.154)$ & 0.161 \\
\hline Gross appearance & & 0.000 & & 0.000 \\
\hline Borrmann types I & 1 (Ref) & & 1 (Ref) & \\
\hline Borrmann types ॥ & $1.080(0.824-1.416)$ & 0.576 & $0.979(0.740-1.294)$ & 0.879 \\
\hline Borrmann types III & $1.723(1.364-2.175)$ & 0.000 & $1.601(1.253-2.046)$ & 0.000 \\
\hline Borrmann types IV & $2.141(1.507-3.044)$ & 0.000 & $1.282(0.841-1.952)$ & 0.248 \\
\hline Tumour stage & & 0.000 & & 0.651 \\
\hline $\mathrm{T} 1$ & 1 (Ref) & & 1 (Ref) & \\
\hline $\mathrm{T} 2$ & $0.855(0.638-1.146)$ & 0.295 & $0.799(0.590-1.082)$ & 0.146 \\
\hline $\mathrm{T} 3$ & $1.262(0.956-1.615)$ & 0.064 & $0.917(0.698-1.205)$ & 0.535 \\
\hline $\mathrm{T} 4$ & $1.867(1.284-2.716)$ & 0.001 & $1.005(0.657-1.537)$ & 0.983 \\
\hline Clinical node status & & 0.372 & & 0.438 \\
\hline Negative & 1 (Ref) & & 1 (Ref) & \\
\hline Positive & $1.376(0.683-2.770)$ & 0.372 & $1.652(0.794-3.436)$ & 0.438 \\
\hline Lymph-node stage & & 0.000 & & 0.000 \\
\hline NO & 1 (Ref) & & 1 (Ref) & \\
\hline N1 & $1.342(1.082-1.666)$ & 0.008 & $1.119(0.863-1.450)$ & 0.397 \\
\hline N2 & $1.480(1.099-1.994)$ & 0.010 & $1.238(0.889-1.725)$ & 0.206 \\
\hline N3 & $3.603(2.497-5.199)$ & 0.000 & $2.653(1.684-4.179)$ & 0.000 \\
\hline Histological type(\%) & & 0.221 & & 0.556 \\
\hline Differentiated & 1 (Ref) & & 1 (Ref) & \\
\hline Undifferentiated & $1.177(0.591-1.529)$ & 0.221 & $0.897(0.624-1.289)$ & 0.556 \\
\hline Joint organ removal & & 0.000 & & 0.000 \\
\hline None & 1 (Ref) & & 1 (Ref) & \\
\hline Pancreas or spleen & $1.964(1.374-2.808)$ & 0.000 & $1.364(0.902-2.062)$ & 0.141 \\
\hline Liver or gall & $1.380(0.896-2.125)$ & 0.144 & $1.291(0.823-2.023)$ & 0.266 \\
\hline Transverse colon & $1.882(1.321-2.681)$ & 0.000 & $1.446(0.984-2.125)$ & 0.060 \\
\hline Gastrectomy & & 0.000 & & 0.001 \\
\hline Total & 1 (Ref) & & 1 (Ref) & \\
\hline Subtotal & $0.549(0.422-0.714)$ & 0.000 & $0.833(0.563-1.233)$ & 0.001 \\
\hline Blood transfusion & & 0.356 & & 0.580 \\
\hline No & 1 (Ref) & & 1 (Ref) & \\
\hline Yes & $1.094(0.904-1.324)$ & 0.356 & $1.003(0.815-1.234)$ & 0.580 \\
\hline Blood loss & & 0.789 & & 0.199 \\
\hline$\leq 200 \mathrm{ml}$ & 1 (Ref) & & 1 (Ref) & \\
\hline $200-400 \mathrm{ml}$ & $0.901(0.723-1.122)$ & 0.350 & $0.900(0.715-1.134)$ & 0.373 \\
\hline$>400 \mathrm{ml}$ & $1.049(0.816-1.347)$ & 0.710 & $0.736(0.552-0.980)$ & 0.036 \\
\hline
\end{tabular}


Table 2: HR for death in intention-to-treat population $(n=567)$-univariable and multivariable analyses (Continued)

\begin{tabular}{cllll}
\hline Lymph node dissection & \multicolumn{1}{c}{$\mathbf{0 . 0 0 4}$} & $\mathbf{0 . 0 4 5}$ \\
D1 & 1 (Ref) & & 1 (Ref) & \\
D2 & $1.019(0.815-1.275)$ & 0.869 & $1.024(0.801-1.308)$ & 0.851 \\
D3 & $0.708(0.560-0.894)$ & 0.004 & $0.771(0.599-0.992)$ & 0.043 \\
\hline
\end{tabular}

Ref = reference category.

*Derived from tests of HR for prognostic factors in univariate model adjusted for treatment group in Cox proportional-hazards model.

tCox-regression analysis, controlling for prognostic factors listed in table.

Table 3 Tests for Heterogeneity of Treatment Effect According to the Clinicopathological Characteristics of the D1 and D3 Patients.

\begin{tabular}{|c|c|c|c|c|}
\hline \multirow[t]{2}{*}{ Subgroup } & D1 surgery & D3 surgery & HR $(95 \% \mathrm{Cl})$ & $\mathbf{P}$ \\
\hline & \multicolumn{3}{|c|}{ No. of deaths/no. of patients } & \\
\hline Total & $150 / 187$ & $137 / 191$ & $1.407(1.113-1.779)$ & \\
\hline \multicolumn{5}{|l|}{ Age (years) } \\
\hline$\leq 55$ & $49 / 66$ & 70/107 & $1.384(0.955-2.004)$ & 0.086 \\
\hline$>55$ & $101 / 121$ & $67 / 84$ & $1.242(0.911-1.693)$ & 0.170 \\
\hline \multicolumn{5}{|l|}{ Sex } \\
\hline Women & $41 / 51$ & $44 / 58$ & $1.248(0.815-1.912)$ & 0.309 \\
\hline Men & 109/136 & $93 / 133$ & $1.463(1.103-1.939)$ & $0.008^{*}$ \\
\hline \multicolumn{5}{|l|}{ Tumor size } \\
\hline$\leq 5$ & $91 / 125$ & $74 / 113$ & $1.401(1.028-1.910)$ & $0.033^{*}$ \\
\hline $5-7$ & $30 / 32$ & $42 / 50$ & $1.412(0.875-2.279)$ & 0.158 \\
\hline$>7$ & $29 / 30$ & $21 / 28$ & $1.917(1.075-3.419)$ & $0.027^{*}$ \\
\hline \multicolumn{5}{|l|}{ Tumour site } \\
\hline Upper stomach & $40 / 44$ & $37 / 42$ & $1.116(0.707-1.762)$ & 0.638 \\
\hline Middle stomach & $35 / 43$ & $29 / 45$ & $1.641(0.984-2.735)$ & 0.058 \\
\hline Lower stomach & $64 / 88$ & $59 / 90$ & $1.482(1.038-2.117)$ & $0.030^{*}$ \\
\hline Whole stomach & $11 / 12$ & $12 / 14$ & $1.574(0.685-3.618)$ & 0.286 \\
\hline \multicolumn{5}{|l|}{ Gross appearance } \\
\hline Borrmann types I & $37 / 58$ & $35 / 54$ & $1.100(0.688-1.759)$ & 0.691 \\
\hline Borrmann types ॥ & $33 / 41$ & $32 / 43$ & $1.781(1.069-2.967)$ & $0.027^{*}$ \\
\hline Borrmann types III & $66 / 73$ & $56 / 77$ & $1.685(1.175-2.416)$ & $0.005^{*}$ \\
\hline Borrmann types IV & $14 / 15$ & $14 / 17$ & $1.708(0.810-3.600)$ & 0.160 \\
\hline \multicolumn{5}{|l|}{ Tumour stage } \\
\hline $\mathrm{T} 1$ & $29 / 41$ & $24 / 44$ & $1.723(0.992-2.992)$ & 0.054 \\
\hline $\mathrm{T} 2$ & $30 / 44$ & $29 / 42$ & $1.282(0.754-2.178)$ & 0.359 \\
\hline $\mathrm{T} 3$ & $79 / 89$ & $71 / 92$ & $1.431(1.037-1.977)$ & $0.029^{*}$ \\
\hline $\mathrm{T} 4$ & $12 / 13$ & $13 / 13$ & $1.071(0.485-2.365)$ & 0.866 \\
\hline \multicolumn{5}{|l|}{ Clinical node status } \\
\hline Negative & $4 / 5$ & $2 / 5$ & $3.070(0.533-17.703)$ & 0.209 \\
\hline Positive & $146 / 182$ & 135/186 & $1.382(1.091-1.752)$ & $0.007^{*}$ \\
\hline \multicolumn{5}{|l|}{ Lymph-node stage } \\
\hline No & $50 / 69$ & $42 / 69$ & $1.781(1.168-2.718)$ & $0.007^{*}$ \\
\hline N1 & $64 / 75$ & $60 / 81$ & $1.504(1.055-2.145)$ & $0.024^{*}$ \\
\hline N2 & $24 / 30$ & $19 / 24$ & $1.116(0.609-2.044)$ & 0.723 \\
\hline N3 & $12 / 13$ & $16 / 17$ & $0.369(0.162-0.841) \dagger$ & $0.018^{*}$ \\
\hline \multicolumn{5}{|l|}{ Histological type } \\
\hline Differentiated & $62 / 99$ & $49 / 82$ & $1.143(0.761-1.563)$ & 0.231 \\
\hline Undifferentiated & 62/99 50/88 & 49/82 56/109 & $1.047(0.773-1.732)$ & 0.334 \\
\hline
\end{tabular}


Table 3: Tests for Heterogeneity of Treatment Effect According to the Clinicopathological Characteristics of the D1 and D3 Patients. (Continued)

Joint organ removal

$\begin{array}{lll}\text { None } & 127 / 160 & 104 / 157 \\ \text { Pancreas or spleen } & 6 / 7 & 14 / 14 \\ \text { Liver or gall } & 9 / 11 & 9 / 9 \\ \text { Transverse colon } & 8 / 9 & 10 / 11\end{array}$

\section{Gastrectomy}

$\begin{array}{lll}\text { Total } & 20 / 22 & 26 / 29 \\ \text { Subtotal } & 130 / 165 & 111 / 162\end{array}$

Blood transfusion

No

Yes

63/87 52/80

$85 / 111$

$\begin{array}{ll}1.703(1.309-2.217) & 0.000^{*} \\ 0.754(0.285-1.996) & 0.569\end{array}$

$0.532(0.200-1.415) \quad 0.206$

$0.403(0.144-1.133) \quad 0.085$

Blood loss

\begin{tabular}{|c|c|c|c|c|}
\hline$\leq 200$ & $41 / 54$ & $41 / 49$ & $0.858(0.555-1.328)$ & 0.493 \\
\hline $200-400$ & $68 / 88$ & $56 / 83$ & $1.623(1.130-2.332)$ & $0.009^{*}$ \\
\hline$>400$ & $41 / 45$ & $40 / 59$ & $2.060(1.327-3.198)$ & \\
\hline
\end{tabular}

The P values are for hazard ratios for death in the group assigned to D1 lymphadenectomy and the group assigned to D3 lymphadenectomy, with $95 \%$ confidence intervals.

The surgery is better for D1 lymphadenectomy when the HR is $<1$; and is better for D3 lymphadenectomy when the HR is $>1$.

†Significantly better for D1 lymphadenectomy.

*Considered significant.

Table 4 Tests for Heterogeneity of Treatment Effect According to the Clinicopathological Characteristics of the D1 and D2 Patients.

\begin{tabular}{|c|c|c|c|c|}
\hline \multirow[t]{2}{*}{ Subgroup } & D1 surgery & D2 surgery & HR $(95 \% \mathrm{Cl})$ & $p$ \\
\hline & \multicolumn{3}{|c|}{ No. of deaths/no. of patients } & \\
\hline Total & $150 / 187$ & 157/189 & $0.982(0.785-1.229)$ & \\
\hline \multicolumn{5}{|l|}{ Age (years) } \\
\hline$\leq 55$ & $49 / 66$ & $88 / 107$ & $0.877(0.618-1.244)$ & 0.462 \\
\hline$>55$ & $101 / 121$ & $69 / 82$ & $1.016(0.748-1.380)$ & 0.919 \\
\hline \multicolumn{5}{|l|}{ Sex } \\
\hline Women & $41 / 51$ & $40 / 52$ & $1.308(0.843-2.029)$ & 0.231 \\
\hline Men & 109/136 & $117 / 137$ & $0.878(0.676-1.140)$ & 0.329 \\
\hline \multicolumn{5}{|l|}{ Tumor size } \\
\hline$\leq 5$ & $91 / 125$ & $97 / 121$ & $0.921(0.692-1.227)$ & 0.575 \\
\hline $5-7$ & $30 / 32$ & $34 / 40$ & $1.178(0.714-1.941)$ & 0.522 \\
\hline$>7$ & $29 / 30$ & $26 / 28$ & $1.143(0.672-1.945)$ & 0.622 \\
\hline \multicolumn{5}{|l|}{ Tumour site } \\
\hline Upper stomach & $40 / 44$ & $32 / 39$ & $1.205(0.752-1.930)$ & 0.438 \\
\hline Middle stomach & $35 / 43$ & $41 / 50$ & $1.086(0.691-1.706)$ & 0.721 \\
\hline Lower stomach & $64 / 88$ & $72 / 87$ & $0.806(0.575-1.130)$ & 0.212 \\
\hline Whole stomach & $11 / 12$ & $12 / 13$ & $1.062(0.464-2.429)$ & 0.887 \\
\hline \multicolumn{5}{|l|}{ Gross appearance } \\
\hline Borrmann types I & $37 / 58$ & $45 / 55$ & $0.618(0.399-0.958)+$ & $0.031^{*}$ \\
\hline Borrmann types ॥ & $33 / 41$ & $31 / 44$ & $1.189(0.727-1.945)$ & 0.490 \\
\hline Borrmann types III & $66 / 73$ & $66 / 74$ & $1.327(0.938-1.878)$ & 0.110 \\
\hline Borrmann types IV & $14 / 15$ & $15 / 16$ & $1.105(0.528-2.312)$ & 0.791 \\
\hline \multicolumn{5}{|l|}{ Tumour stage } \\
\hline $\mathrm{T} 1$ & $29 / 41$ & $35 / 40$ & $0.755(0.458-1.243)$ & 0.269 \\
\hline $\mathrm{T} 2$ & $30 / 44$ & $32 / 45$ & $1.093(0.661-1.808)$ & 0.729 \\
\hline T3 & $79 / 89$ & $75 / 87$ & $1.073(0.782-1.473)$ & 0.662 \\
\hline T4 & $12 / 13$ & $15 / 17$ & $0.854(0.383-1.906)$ & 0.700 \\
\hline
\end{tabular}


Table 4: Tests for Heterogeneity of Treatment Effect According to the Clinicopathological Characteristics of the D1 and D2 Patients. (Continued)

\begin{tabular}{|c|c|c|c|c|}
\hline \multicolumn{5}{|l|}{ Clinical node status } \\
\hline Negative & $4 / 5$ & $2 / 3$ & $2.654(0.458-15.362)$ & 0.276 \\
\hline Positive & $146 / 182$ & $155 / 186$ & $0.965(0.770-1.210)$ & 0.759 \\
\hline \multicolumn{5}{|l|}{ Lymph-node stage } \\
\hline No & $50 / 69$ & $46 / 60$ & $1.004(0.672-1.500)$ & 0.984 \\
\hline N1 & $64 / 75$ & $80 / 93$ & $1.040(0.748-1.446)$ & 0.814 \\
\hline N2 & $24 / 30$ & $21 / 26$ & $0.820(0.455-1.477)$ & 0.508 \\
\hline N3 & $12 / 13$ & $10 / 10$ & $0.376(0.153-0.922) \dagger$ & $0.033^{*}$ \\
\hline \multicolumn{5}{|l|}{ Histological type } \\
\hline Differentiated & $62 / 99$ & $55 / 88$ & $1.033(0.921-1.783)$ & 0.136 \\
\hline Undifferentiated & $50 / 88$ & $56 / 101$ & $1.157(0.833-1.947)$ & 0.390 \\
\hline \multicolumn{5}{|l|}{ Joint organ removal } \\
\hline None & $127 / 160$ & $124 / 148$ & $0.960(0.749-1.229)$ & 0.745 \\
\hline Pancreas or spleen & $6 / 7$ & $13 / 16$ & $1.340(0.502-3.575)$ & 0.559 \\
\hline Liver or gall & $9 / 11$ & $4 / 8$ & $2.959(0.796-10.992)$ & 0.105 \\
\hline Transverse colon & $8 / 9$ & $16 / 17$ & $0.659(0.277-1.566)$ & 0.345 \\
\hline \multicolumn{5}{|l|}{ Gastrectomy } \\
\hline Total & $20 / 22$ & $20 / 21$ & $1.089(0.583-2.036)$ & 0.788 \\
\hline Subtotal & $130 / 165$ & $137 / 168$ & $0.970(0.763-1.233)$ & 0.802 \\
\hline \multicolumn{5}{|l|}{ Blood transfusion } \\
\hline No & $63 / 87$ & $70 / 85$ & $0.900(0.640-1.265)$ & 0.543 \\
\hline Yes & $87 / 100$ & $87 / 104$ & $1.056(0.785-1.422)$ & 0.718 \\
\hline \multicolumn{5}{|l|}{ Blood loss } \\
\hline$\leq 200$ & $41 / 54$ & $57 / 70$ & 0.920(0.616-1.375) & 0.685 \\
\hline $200-400$ & $68 / 88$ & $67 / 73$ & $0.703(0.501-0.986)+$ & $0.041^{*}$ \\
\hline$>400$ & $41 / 45$ & $33 / 46$ & $1.870(1.175-2.977)$ & $0.008^{*}$ \\
\hline
\end{tabular}

The $\mathrm{P}$ values are for hazard ratios for death in the group assigned to D1 lymphadenectomy and the group assigned to D2 lymphadenectomy, with $95 \%$ confidence intervals.

The surgery is better for D1 lymphadenectomy when the HR is $<1$; and is better for D2 lymphadenectomy when the HR is $>1$. †Significantly better for D1 lymphadenectomy.

*Considered significant.

Furthermore, no significant difference was found in the incident rates of major surgery-related complications between the two groups, which was similar to the results in the trials done in Hong Kong,[14] the UK,[5] and Dutch[15].

We conducted a post hoc subgroup analysis including thirteen variables. To be interest, the results indicated that D1 surgery got significantly more benefit than D3 surgery for N3 disease, while D3 surgery has significantly more benefit than D1 surgery in the subgroups of N0 and N1 disease. Since this result was from a post hoc subgroup, it might be a false positive owing to multiple testing,[16] the possible survival benefit of D3 lymphadenectomy in node-negative patients will need to be clarified in further studies.

In a review article, Sun Hu Yang et alreported that there was no difference in the 3- or 5-year survival between D1 and D2[17]. In the study, the 5-year overall survival was $37.4 \%$ for D1 group and $48.7 \%$ for D3 group, and the period of diagnosis didn't affect survival $(\mathrm{p}=0.084, \log$-rank test $)[18]$. It can be seen that longterm survival is lower, when comparing our results with historical report, in which the observed 5-year survival rates were $53.6 \%$ and $59.5 \%$, respectively[13]. This result indicated that the time of diagnosis of malignant tumours as well as gastric cancer is much later in China than in other countries, especially western countries.

In this study, we found that more than $60 \%$ of both the D1 and D3 patients had lymph node metastases which was higher than the report of Bunt et al[19]. In the D3 group, which includes lymph node dissection of the N1, N2 and N3 level, there were $42 \%$ being classified as $\mathrm{N} 1,13 \%$ as $\mathrm{N} 2$, and $9 \%$ as $\mathrm{N} 3$. The extended surgery is considered to be related to the risk of operative morbidity and mortality[6]. The mortality for gastrectomy in Western countries was usually5\% and even approaches $16 \%$ in some trials[7-9].

Robert C G et al reported that the overall 5-year survival rate for the 286 patients undergoing gastrectomy with additional organ resection was $32 \%$, which was 
significantly less than the gastrectomy-alone group[20]. Besides the surgery extent, the participating surgeons' operative skill and experience, and the workload cases are also important factors for survival rates[21,22]. There are many studies having reported a relationship between the number of cases treated in a hospital and the outcomes of cancer treatment[22-27]. Moreover, the uniformity of treatment is also important. Our study was carried out in a hospital that performs a high volume of nodal dissections for gastric cancer with low morbidity and mortality rates. In our study, all participating surgeons were of the same department, which minimizes the variation in individual operating skill and management, and did an equal number of D1 and D3 resections during the trial, which balances the comparisons between the two groups without bias to individual surgeons' skill. Therefore, the experience as a result of caseload, surgical skill, and the case selection are very important[5,28,29].

\section{Conclusions}

As D3 gastrectomy is associated with low mortality and adequate survival time when performed in selected institutions that have had sufficient experience with the operation and with post-operative management, we recommend D3 lymphadenectomy for patients with curable gastric cancer except for patients with Borrmann I disease who are more suitable for D1 surgery.

\section{Acknowledgements}

This work was supported in part by China National Natural Science Foundation (30772100). The study was supported by a grant from the Science and Technology Program of Shenyang (No.1081232-1-00), and the study was supported by a grant from the Science and Technology Program of Shenyang (No.1071166-9-00).

\section{Author details}

'Department of Surgery Oncology, General Surgery, First Hospital of China Medical University, Shenyang, China. ${ }^{2}$ Department of Cardiology, First Hospital of China Medical University, Shenyang, China. ${ }^{3}$ Department of Orthopaedics, First Hospital of China Medical University, Shenyang, China. ${ }^{4}$ Department of Anesthesiology, First Hospital of China Medical University, Shenyang, China.

\section{Authors' contributions}

$\mathrm{HZ}$ and $\mathrm{PL}$ participated in the design of the study. $\mathrm{HZ}$ and DW performed the statistical analysis and drafted the manuscript. CGL, YM, RNS, and SBW participated in the coordination of the study. All authors read and approved the final manuscript.

\section{Competing interests}

The authors declare that they have no competing interests.

Received: 9 September 2009 Accepted: 20 June 2010 Published: 20 June 2010

\section{References}

1. Japanese Research Society for Gastric Cancer: Japanese classification of gastric cancer, 1st English edn. Tokyo:Kanehara 1995.
2. Maruyama $\mathrm{K}$, Kobayashi $\mathrm{O}$, Kinoshita T: Progress in gastric cancer surgery in Japan and its limits on radicality. World J Surg 1987, 11:418-25.

3. de Aretxabala X, Konishi K, Yonemura Y, Ueno K, Yagi M, Noguchi M, Miwa K, Miyazaki I: Node dissection in gastric cancer. Br J Surg 1987, 74:770-73

4. Hartgrink $\mathrm{HH}$, van de Velde $\mathrm{CJ}$, Putter $\mathrm{H}$, Bonenkamp JJ, Klein Kranenbarg $\mathrm{E}_{\text {, }}$ Songun I, Welvaart K, van Krieken JH, Meijer S, Plukker JT, van Elk PJ, Obertop H, Gouma DJ, van Lanschot JJ, Taat CW, de Graaf PW, von Meyenfeldt MF, Tilanus H, Sasako M: Extended lymph node dissection for gastric cancer: who may benefit? Final results of the randomized Dutch Gastric Cancer Group trial. J Clin Oncol 2004, 22:2069-77.

5. Cuschieri A, Fayers P, Fielding J, Craven J, Bancewicz J, Joypaul V, Cook P: Patient survival after D1 and D2 resections for gastric cancer: long-term results of the MRC randomised surgical trial. Br J Cancer 1999, 79:1522-30.

6. Wu CW, Chang IS, Lo SS, Hsieh MC, Chen JH, Lui WY, Whang-Peng J: Complications following D3 gastrectomy: post hoc analysis of a randomised trial. World J Surg 2006, 30:12-16.

7. Msika S, Benhamiche AM, Tazi MA, Rat P, Faivre J: Improvement of operative mortality after curative resection for gastric cancer: Populationbased study. World I Surg 2000, 24:1137-1142.

8. Wanebo HJ, Kennedy BJ, Chmiel J, Steele G Jr, Winchester D, Osteen R: Cancer of the stomach: A patient care study by the American College of Surgeons. Ann Surg 1993, 218:583-592.

9. McCulloch P: Should general surgeons treat gastric carcinoma? An audit of practice and results, 1980-1985. Br J Surg 1994, 81:417-420.

10. Sano T, Sasako M, Yamamoto $S$, Nashimoto A, Kurita A, Hiratsuka M, Tsujinaka T, Kinoshita T, Arai K, Yamamura Y, Okajima K: Gastric cancer surgery: morbidity and mortality results from a prospective randomized controlled trial comparing D2 and extended para-aortic lymphadenectomy-Japan Clinical Oncology Group study 9501. J Clin Oncol 2004, 22:2767-73.

11. Wu CW, Chiou JM, Ko FS, Lo SS, Chen JH, Lui WY, Whang-Peng J: Quality of life after curative gastrectomy for gastric cancer in a randomised controlled trial. British Journal of Cancer 2008, 98:54-59.

12. Wu CW, Hsieh MC, Lo SS, Tsay SH, Li AF, Lui WY, P'eng FK: Prognostic indicators in patients with gastric cancer after resection for patients with carcinoma of the stomach. Dig Dis Sci 42:1265-1269.

13. Wu CW, Hsiung CA, Lo SS, Hsieh MC, Chen JH, Li AF, Lui WY, WhangPeng J: Nodal dissection for patients with gastric cancer: a randomised controlled trial. Lancet Oncol 7:309-315.

14. Robertson CS, Chung SC, Woods SD, Griffin SM, Raimes SA, Lau JT, Li AK: A prospective randomized trial comparing $\mathrm{R} 1$ subtotal gastrectomy with R3 total gastrectomy for antral cancer. Ann Surg 1994, 220:176-82.

15. Bonenkamp JJ, Hermans J, Sasako M, van de Velde CJH, Dutch Gastric Cancer Group: Extended lymph-node dissection for gastric cancer. N Engl J Med 1999, 340:908-14.

16. Sasako M, Sano T, Yamamoto S, Kurokawa Y, Nashimoto A, Kurita A, Hiratsuka M, Tsujinaka T, Kinoshita T, Arai K, Yamamura Y, Okajima K, Japan Clinical Oncology Group: D2 Lymphadenectomy Alone or with Para-aortic Nodal Dissection for Gastric Cancer. N Engl J Med 2008, 359:453-62.

17. Yang SH, Zhang YC, Yang KH, Li YP, He XD, Tian JH, Lv TH, Hui YH, Sharma N: An evidence-based medicine review of lymphadenectomy extent for gastric cancer. The American Journal of Surgery 2009, 197:246-251.

18. Crane SJ, Locke GR, Harmsen WS, Zinsmeister AR, Romero Y, Talley NJ: Survival Trends in Patients With Gastric and Esophageal Adenocarcinomas: A Population-Based Study. Mayo Clin Proc 2008, 83(10):1087-1094.

19. Bunt AM, Hermans J, van de Velde CJ, Sasako M, Hoefsloot FA, Fleuren G, Bruijn JA: Lymph node retrieval in a randomized trial on western-type versus Japanese-type surgery in gastric cancer. J Clin Oncol 1996, 14(8):2289-94.

20. Robert CGMartin II, Jaques PDavid, Brennan FMurray, Karpeh Martin: Extended Local Resection for Advanced Gastric Cancer Increased Survival Versus Increased Morbidity. Ann Surg 2002, 236(2):159-65.

21. Davis $P$, Sano $T$ : The difference in gastric cancer between Japan, USA and Europe: What are the facts? What are the suggestions? Crit Rev Oncol Hematol 2001, 40:77-94.

22. Birkmeyer JD, Siewers AE, Finlayson EV, Stukel TA, Lucas FL, Batista I, Welch HG, Wennberg DE: Hospital volume and surgical mortality in the United States. N Engl J Med 2002, 346:1128-1137. 
23. Bach PB, Cramer LD, Schrag D, Downey RJ, Gelfand SE, Begg CB: The influence of hospital volume on survival after resection for lung cancer. N Engl J Med 2001, 345:181-8.

24. Schrag D, Cramer LD, Bach PB, Cohen AM, Warren JL, Begg CB: Influence of hospital procedure volume on outcomes following surgery for colon cancer. JAMA 2000, 284:3028-35.

25. Begg CB, Cramer LD, Hoskins WJ, Brennan MF: Impact of hospital volume on operative mortality for major cancer surgery. JAMA 1998, 280:1747-51.

26. Hillner BE, Smith TJ, Desch CE: Hospital and physician volume or specialization and outcomes in cancer treatment: importance in quality of cancer care. J Clin Oncol 2000, 18:2327-40.

27. Birkmeyer JD, Sun Y, Wong SL, Stukel TA: Hospital volume and late survival after cancer surgery. Ann Surg 2007, 245(5):777-83.

28. Wu CW, Hsieh MC, Lo SS, Wang LS, Hsu WH, Lui WY, Huang MH, P'eng FK Morbidity and mortality after radical gastrectomy for patients with carcinoma of the stomach. J Am Coll Surg 1995, 181:26-32.

29. McCulloch P, Niita ME, Kazi H, Gama-Rodrigues JJ: Gastrectomy with extended lymphadenectomy for primary treatment of gastric cancer. $\mathrm{Br}$ J Surg 2005, 92:5-13.

\section{Pre-publication history}

The pre-publication history for this paper can be accessed here: http://www.biomedcentral.com/1471-2407/10/308/prepub

doi:10.1186/1471-2407-10-308

Cite this article as: Zhang et al:: Does D3 surgery offer a better survival outcome compared to D1 surgery for gastric cancer? A result based on a hospital population of two decades as taking D2 surgery for reference. BMC Cancer 2010 10:308.

\section{Submit your next manuscript to BioMed Central and take full advantage of:}

- Convenient online submission

- Thorough peer review

- No space constraints or color figure charges

- Immediate publication on acceptance

- Inclusion in PubMed, CAS, Scopus and Google Scholar

- Research which is freely available for redistribution

Submit your manuscript at www.biomedcentral.com/submit 